\title{
An assessment of threats to Anatidae in Iran
}

\author{
ELHAM NOURANI, MOHAMMAD KABOLI and BEN COLLEN
}

\section{Summary}

The network of wetland systems in Iran provides valuable staging and wintering areas for waterbirds in the African-Western Eurasian flyways. The West Siberian/Caspian/Nile populations of Anatidae (ducks, geese and swans) regularly overwinter and stop over in Iran, and are considered an economically and culturally important group of birds in the country. Conservation of such migratory birds requires the identification of key threat factors impacting them throughout the flyway. Since documented data on the status and threats facing Anatidae in Iran are very scarce, in this paper, we attempted to determine the general population trends for the 26 Anatidae species in Iran, using annual waterbird census data, and to identify and score the most important threat factors affecting each species, by consulting the top ornithologists and professional birdwatchers in the country by means of a survey. Our results indicate that the most prevalent threats affecting all 26 species are dam construction, water management practices, and hunting. Our results provide the necessary material for Red List assessment of these species at the national level, an important tool for conservation priority setting within Iran and in the flyway.

\section{Introduction}

Waterbirds have long been the subject of many international conservation agreements. The Convention on Wetlands (Ramsar, Iran, 1971) and the Agreement on the Conservation of AfricanEurasian Migratory Waterbirds (AEWA, 1999), among others, urge countries to work together to save migratory waterbirds through the flyway concept. Flyways are defined as "the biological systems of migration paths that directly link sites and ecosystems in different countries and continents" (Boere and Stroud 2006). Implementing conservation actions for migratory waterbirds according to the flyway concept can simplify the complexities of migration and contribute to consistent international cooperation between governments and conservation organizations around the world.

The Anatidae (ducks, geese, and swans) is an economically and culturally important family of waterbirds of the African-Western Eurasian flyways. Their status is widely unfavourable, with an overall $43 \%$ decrease in the 121 Anatidae populations of the AEWA region (Davidson and Stroud 2006). Swans and migratory geese, with $25 \%$ and $23 \%$ of populations declining respectively, have a better status in this region than do migratory ducks, with $44 \%$ of their populations thought to be in decline. Ducks that depend on West Asia/Middle East and Africa during their non-breeding season are thought to be particularly threatened (Davidson and Stroud 2006).

Iran, with its numerous wetland systems, serves as an important staging and wintering area on the African-Western Eurasian flyways. It is the country with the most numerous Important Bird Areas (IBAs) in the Middle East (BirdLife International 2013) and has the highest richness of migratory species in the Middle East region (Kirby et al. 2008). Iran is a key country supporting the Western Siberian/Caspian/Nile population of Anatidae (Fig. I). Overall, 35 species of Anatidae have been recorded in Iran of which 26 regularly occur in the country (Kaboli et al. 2012). The globally 'Endangered' (EN) White-headed Duck Oxyura leucocephala regularly breeds and 


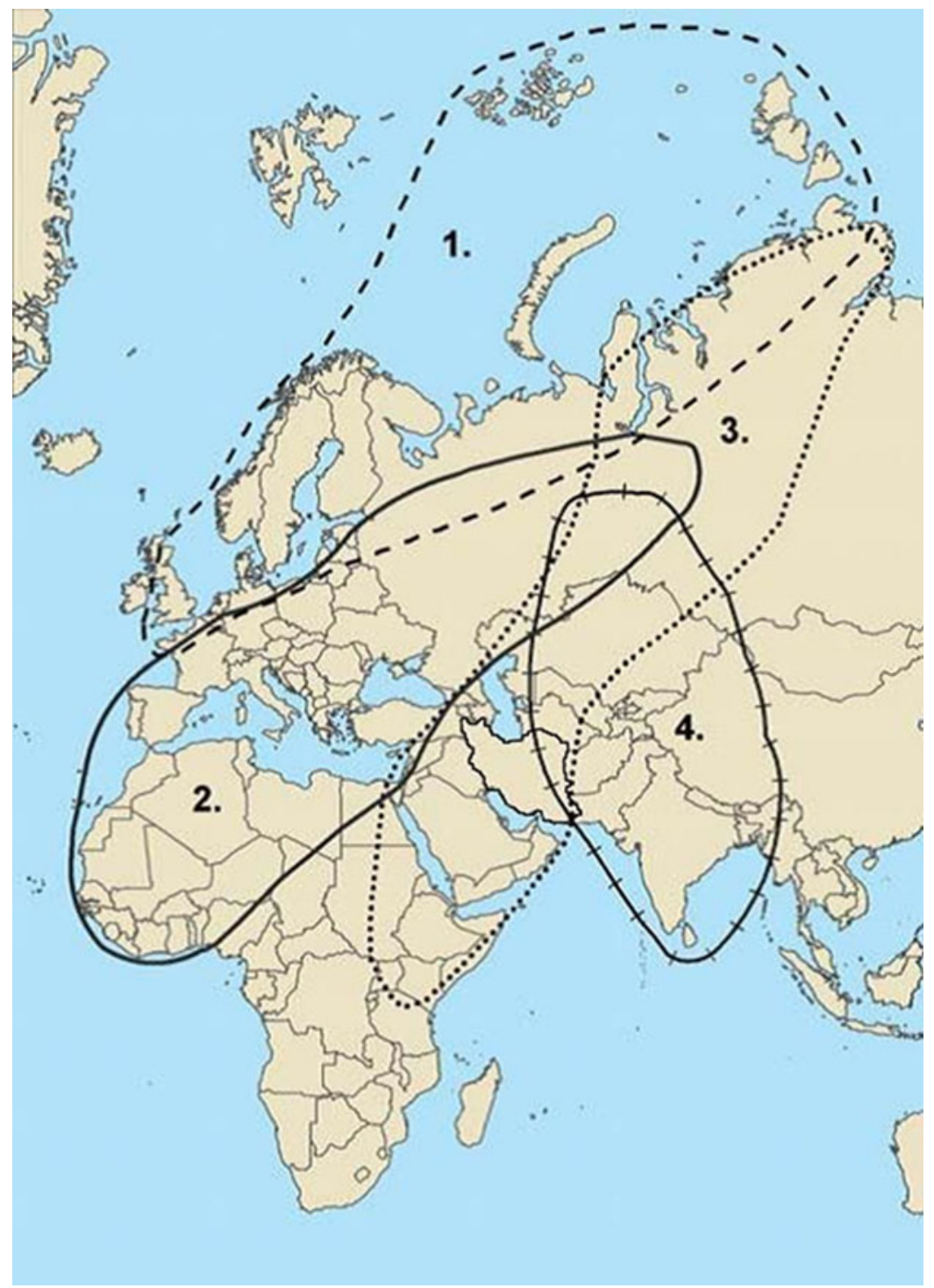

Figure 1. Main geographical populations of Anatidae in western Eurasia: 1. Northern White Sea/ North Sea population, 2. European Siberia/Black Sea-Mediterranean population, 3. West Siberian/ Caspian/Nile population, and 4. Siberian-Kazakhstan/Pakistan-India population (Isakov 1967, Boere and Stroud 2006). Iran (solid borderlines) is located within the Western Siberian/Caspian/Nile flyway.

winters in Iran. Other globally threatened species regularly occurring in Iran include Marbled Teal Marmaronetta angustirostris (VU), a breeding and wintering visitor (Scott and Rose 1996, Kaboli et al. 2012) and Lesser White-fronted Goose Anser erythtopus (VU), another common winter visitor (Mansoori and Amini 2011, Kaboli et al. 2012). Anatidae species that are recorded as vagrants in Iran include Bean Goose Anser fabalis, Red-breasted Goose Branta ruficollis, Barnacle Goose B. leucopsis, Light-bellied Brent Goose B. hrota, Cotton Pygmy-goose Nettapus coromandelianus, Long-tailed Duck Clangula hyemalis, Common Scoter Melanitta nigra, and 
Velvet Scoter M. fusca (Roselaar and Aliabadian 2009, Khaleghizadeh et al. 2011). Old records of Falcated Duck Anas falcata in Iran prior to 196os were recently reassessed by Roselaar and Aliabadian (2009) and were considered insufficient to confirm the past occurrence of this species in Iran.

The largest concentrations of migratory Anatidae in Iran occur in the wetlands of the north, across the southern Caspian lowlands (Mansoori 2009), but many of the species are also observed in suitable water bodies throughout the country. Since Anatidae species are dependent on wetland habitats which are rather discrete and far apart (Scott and Rose 1996), the extent of occurrence of many of these species in Iran is relatively large and the critical resources they use are scattered throughout this area in a fragmented nature, making them potentially vulnerable to a variety of threats.

Since the 1970s, various threats affecting wetlands - the most important habitats for Anatidae have been identified in Iran. The most important threats to most wetlands have been identified as drainage and reclamation (Evans 1994, Scott 1995, Behrouzi-Rad 2008). However, identifying broad-scale threatening processes at a habitat scale is often not considered sufficient to implement conservation action. While a threat may be present over a broad area, species-specific responses to that threat can be highly variable, mediated by biology, environment and exposure. Thus understanding species level threats and quantifying the processes that lead to a given level of extinction risk is of great value. The current system for management status classification in Iran consists of three categories: protected, endangered, and unprotected. The latest version of the list of wildlife status that was compiled in 1999 by the Department of Environment (DOE 2004) serves as the only source for determining extinction risk and conservation status of waterbirds in Iran. Although this list has legal status, the criteria that have led to its establishment are not clearly defined by the DOE and the three categories are mostly based on international classifications, which in many cases do not represent the national status of species. Considering the shortcomings of this list, the only remaining source of quantitative data for determining the status of waterbirds in Iran is the annual winter waterbird census carried out in all major wetlands since 1967 (Scott 2010).

The lack of information on the current condition and threats to Anatidae species has hampered assessment of national level extinction risk and conservation priority setting. Moreover, information gathered on threats at the national scale can bolster global scale assessments of extinction risk (Zamin et al. 2010). Identification of threats affecting a group of migratory species within a country facilitates conservation planning both at the flyway and national scales. A clear understanding of key issues affecting migratory populations in any part of a flyway is a necessity for successful conservation (Stroud et al. 2006). Moreover, conservation efforts in one part of a species range are less effective if threats impacting populations and habitats elsewhere are not considered and tackled (Kirby et al. 2008).

With the aim of providing sufficient information for threat assessments of Anatidae species at the national and flyway scale, in the present paper we indicate the status of these species by (i) determining their population trends using three decades of annual waterbird census results and (ii) identifying major threat factors affecting each species in Iran.

\section{Methods}

\section{Identification of population trends}

To provide a general picture of the condition of Anatidae in Iran over the past three decades, we collected DOE waterbird census data from 1982 to 2012 for the 26 species of Anatidae regularly occurring in the country and analysed population trends using the software TRIM (Trends and Indices for Monitoring data) (Pannkoek and van Strien 2005). These censuses are carried out annually by DOE provincial offices in mid-January all over Iran, counting waterbirds occurring at important wetland sites throughout the country. TRIM uses a log-linear Poisson regression to 
model population trends from site-based count data and imputes the missing values using data from other sites in the same year. We excluded years that contained zero observations at the beginning and/or end of the analysed period and calculated trends using the linear trend model setting of TRIM using as many change points as possible (Pannkoek and van Strien 2005) and obtained a value for the average slope of population trend model for the years analysed. This slope was then converted into one of the six trend categories by TRIM: Strong increase (significantly more than $5 \%$ per year), Moderate increase (significant increase, but not significantly more than $5 \%$ per year), Stable (no significant increase or decline, certain to be less than $5 \%$ per year), Uncertain (no significant increase or decline, not certain to be less than $5 \%$ per year), Moderate decline (significant decline, but not significantly more than $5 \%$ per year), and Steep decline (decline significantly more than $5 \%$ per year) (Pannkoek and van Strien 2005).

\section{Identification of threats}

Identification of threats for the purpose of supporting assessment of is usually achieved through reviewing documented and published literature (Kirby et al. 2008, Jennings and Rohr 2011, Croxall et al. 2012). For species or geographical regions with scant data, questionnaires are used to complement the process (Ocock et al. 2006, Goriup and Tucker 2007). Assigning the precise threat determining a decline in population size is a complex and poorly understood process (Di Fonzo et al. 2013). Gathering the views of experts in a structured manner, on what are the probable causes of high extinction risk or decline, is frequently the next best approach, and is employed for the IUCN Red List. As with many countries, published data on threats to Anatidae species in Iran are very scarce. To fill this gap and obtain reliable information about threats affecting each species, we consulted ornithologists of Iran's Department of Environment, including staff at DOE Wildlife Bureaus, local site managers and rangers, and professional birdwatchers through a set of questionnaires (Appendix $\mathrm{S}_{1}$ in the online supplementary material). Based on their academic and professional background, 16 people were identified as knowledgeable and reliable potential contributors. The questionnaires were designed to identify the threats currently facing the 26 species of Anatidae included in this study. To clarify the aims and context of the questionnaire and to determine which threats make Anatidae species susceptible to being categorised as threatened at the national level, we asked respondents to identify threats that they consider to be causing a decline, for species identified as declining through trend analysis, or likely to cause a decline, for species with uncertain, stable, and increasing trends. Threats were defined according to the threat classification scheme devised by Salafsky et al. (2008), which underpins the global, and many national, Red Listing processes (IUCN and CMP 2006, Zamin et al. 2010). The scheme comprises II first level threats, consisting of (I) residential and commercial development, (2) agriculture and aquaculture, (3) energy production and mining, (4) transportation and service corridors, (5) biological resource use, (6) human intrusion and disturbance, (7) natural systems modifications, (8) invasive and other problematic species, (9) pollution, (10) geological events, and (II) climate change and severe weather. Each first level threat is broken down into $2^{\text {nd }}$ and $3^{\text {rd }}$ level categories (we only went down to $2^{\text {nd }}$ level categories for the purpose of this study). Questionnaire respondents were asked to identify the most important $1^{\text {st }}$ and $2^{\text {nd }}$ level threats for each of the 26 species.

Respondents were also asked to provide the timing, scope, and severity of each second level threat using a scoring system developed by Birdlife International (BirdLife International 2010). The impact of each $2^{\text {nd }}$ level threat was scored from o to 3 for timing (past, ongoing, future, etc.), scope (the proportion of the population affected), and severity (how rapidly it is causing, or is likely to cause, a decline in the population) (Appendix S2).

After collecting the questionnaires, the internal consistency of responses was evaluated by computing Cronbach's alpha (Cronbach 1951) for questionnaires filled out for each species. Alpha coefficients range from o to 1 , with higher scores indicating more internal consistency. We used SPSS v. 17.0 (SPSS Inc., Chicago, IL, USA) to calculate alpha and considered 0.7 as the threshold 
for acceptable reliability (Nunnally 1978). After ensuring the reliability of questionnaires, we calculated the average of the impact scores that our respondents assigned for timing, scope, and severity for each of the $2^{\text {nd }}$ level threats and calculated the overall impact of a threat to each species by adding the average scores for timing, scope, and severity (High impact: score 8, 9, Medium impact: score 6, 7, Low impact: score 3, 4, 5, No-negligible impact: score $0,1,2$ ). This technique assumes that timing, scope and severity are of equal importance in determining the threat impact of each species (BirdLife International 2010).

\section{Results}

\section{Trend categories}

We were able to estimate population trends for 25 of the 26 species. Red-crested Pochard Netta rufina was excluded from trend analysis because data on its annual census were not available in the DOE archives. For eight species, the resulting trend was categorised as Uncertain. Three species showed stable populations. Moderate and steep decline categories comprised eight and three species, respectively, and three species were categorised as moderately increasing (Table 1 ).

\section{Threats}

We received Io completed surveys (62.5\% return rate) identifying threats to the 26 Anatidae species. Each respondent completed threat evaluations for all 26 species. Computing Cronbach's alpha showed that internal consistency of all questionnaires was acceptable, ranging from 0.81-0.93 (Table I). Averaging the impact scores for respondents for each species showed that no threat category was considered to have a high impact on Anatidae species in Iran. However, many of the $2^{\text {nd }}$ level threats were scored as having medium impact (Table I). Nine of the II possible $I^{\text {st }}$ level threat categories were identified as affecting the group of Anatidae species we evaluated (Fig. 2). "Geological events" and "Climate change and severe weather" were not identified as a threat to any of the 26 species in Iran. However, climate change may be considered as an over-arching factor that influences some other threats listed. The most common $1^{\text {st }}$ level threat was "Natural systems modifications" affecting all of the species (100\%) with medium impact, followed by "Biological resource use" (25 species, 96\%), "Invasive and other problematic species and diseases" (22 species, 85\%), "Agriculture and aquaculture" (20 species, 77\%), "Pollution" (19 species, 73\%), and "Residential and commercial development," (17 species, $65 \%$ ) were also identified as important medium-impact threats.

For $2^{\text {nd }}$ level threats, "Dams and water management/use," was the most common, affecting all of the species in this review, while "Housing and urban areas," "Wood and pulp plantations," "mining and quarrying," "Recreational activities," and "War, civil unrest and military exercises," were identified as having medium impact on only one species each (0.4\%) (Fig. 3).

Globally threatened species (those classified as Vulnerable, Endangered or Critically Endangered by IUCN) had consistently higher numbers of threats identified as affecting the species in Iran (all had seven level-1 threats identified). Species classified at a global level as Least Concern or Near Threatened had fewer threats on average (mean $=5.59, \mathrm{SE}=0.29$ ), but were notably considered to be impacted by a variety of threats.

\section{Discussion}

The most common threats to Anatidae in Iran were natural systems modification and hunting, the former mostly due to dam construction and unsound water management. Wetland destruction and hunting were identified as serious threats to wetlands and waterbirds during the 1970s (Scott 2007, Derek Scott pers. comm. 2012) and 1990s (Evans 1994, Scott 1995), indicating that although these threats have been identified for several decades, they still remain significant and the populations of most Anatidae species are facing declines or strong fluctuations in the face of 
Table 1. Medium-impact threats to Anatidae species in Iran. Categories of threat follow Salafsky et al. (2008). The trend categories provided by TRIM include: SI= strong increase, $\mathrm{MI}=$ moderate increase, $\mathrm{U}=$ uncertain, $\mathrm{MD}=$ moderate decline, $\mathrm{SD}=$ steep decline, $\mathrm{S}=$ stable.

\begin{tabular}{|c|c|c|c|c|c|c|c|c|c|c|c|c|c|c|c|c|c|c|c|c|c|}
\hline & \multirow[t]{2}{*}{$\begin{array}{l}\text { Red List } \\
\text { Category }\end{array}$} & \multirow[t]{2}{*}{$\begin{array}{l}\text { National } \\
\text { Trend }\end{array}$} & \multirow[t]{2}{*}{ Cronbach's $\alpha$} & \multicolumn{3}{|c|}{$\begin{array}{l}\text { Residential and } \\
\text { commercial } \\
\text { development }\end{array}$} & \multicolumn{4}{|c|}{$\begin{array}{l}\text { Agriculture and } \\
\text { aquaculture }\end{array}$} & \multicolumn{3}{|c|}{$\begin{array}{l}\text { Energy } \\
\text { production } \\
\text { and mining }\end{array}$} & \multicolumn{4}{|c|}{$\begin{array}{l}\text { Transportation and } \\
\text { service corridors }\end{array}$} & \multicolumn{4}{|c|}{$\begin{array}{l}\text { Biological } \\
\text { resource use }\end{array}$} \\
\hline & & & & 1.1 & 1.2 & 1.3 & 2.1 & 2.2 & 2.3 & 2.4 & 3.1 & 3.2 & $3 \cdot 3$ & 4.1 & 4.2 & $4 \cdot 3$ & $4 \cdot 4$ & 5.1 & 5.2 & $5 \cdot 3$ & $5 \cdot 4$ \\
\hline Cygnus olor & LC & $\mathrm{U}$ & 0.88 & & $\times$ & $x$ & & & & $x$ & & & & & $x$ & & & $\times$ & & & \\
\hline C. cygnus & LC & $\mathrm{U}$ & 0.92 & & $x$ & $x$ & & & & $x$ & & & & & $x$ & & & $\times$ & & & \\
\hline C. bewickii & LC & $\mathrm{U}$ & 0.91 & & $x$ & $x$ & & & & $x$ & & & & & $\times$ & & & $\times$ & & & \\
\hline Anser anser & LC & $\mathrm{S}$ & 0.88 & & $x$ & & & & $x$ & & & & & & $x$ & & & $x$ & & & \\
\hline A. albifrons & LC & MD & 0.84 & & $x$ & $x$ & $x$ & & & & & & & & & & & $\times$ & & & \\
\hline A. erythropus & VU & $\mathrm{U}$ & 0.92 & & $x$ & $x$ & & $x$ & & & & & & & & & & $x$ & & & \\
\hline Tadorna tadorna & $\mathrm{LC}$ & MD & 0.88 & & & & $\times$ & & & & & & & & & & & $\times$ & $x$ & & \\
\hline T. ferruginea & LC & $\mathrm{SD}$ & 0.84 & & & & $x$ & & & & & & & & & & & $x$ & $x$ & & \\
\hline Anas platyrhynchos & LC & MD & 0.84 & & $x$ & $x$ & $x$ & & $x$ & & & $x$ & & & & & & $\times$ & & & \\
\hline A. strepera & LC & $\mathrm{S}$ & 0.81 & & $\times$ & $x$ & $\times$ & & $x$ & & $x$ & & & & & & & $\times$ & & & \\
\hline A. acuta & LC & MD & 0.85 & & $x$ & & $x$ & & & & $x$ & & & & & & & $x$ & & & \\
\hline A. clypeata & LC & MD & 0.81 & & $x$ & & & & $x$ & & $x$ & & & & & $x$ & & $x$ & & & \\
\hline A. crecca & LC & $\mathrm{S}$ & 0.84 & & $x$ & & $\times$ & & $x$ & & $x$ & & & & & & & $\times$ & & & \\
\hline A. querquedula & LC & $\mathrm{SD}$ & 0.87 & & $x$ & & $x$ & & & & $x$ & & & & & & & $x$ & & & \\
\hline A. penelope & LC & MD & 0.87 & & $x$ & & & & & & $x$ & & & & & & & $\times$ & & & \\
\hline $\begin{array}{l}\text { Marmaronetta } \\
\text { angustirostris }\end{array}$ & VU & SD & 0.93 & $\times$ & $x$ & & & & $x$ & & & & & & & & & $\times$ & & & \\
\hline A. ferina & $\mathrm{LC}$ & MD & 0.86 & & & & & & $x$ & & & & & & $x$ & & & $\times$ & & & \\
\hline Netta rufina & LC & - & 0.86 & & $\times$ & $x$ & & & $x$ & & $x$ & & & & $\times$ & $x$ & & $\times$ & & & \\
\hline A. marila & LC & $\mathrm{U}$ & 0.90 & & $x$ & & & & & $x$ & $x$ & & & & $x$ & $x$ & & $\times$ & & & \\
\hline Bucephala clangula & LC & MI & 0.86 & & & & & & & $x$ & $x$ & & & & $\times$ & $x$ & & $x$ & & & \\
\hline A. fuligula & $\mathrm{LC}$ & MI & 0.90 & & & & & & & & & & & & & & & $\times$ & & & \\
\hline A. nyroca & NT & MD & 0.90 & & $x$ & & & & & & & & & & & & & $x$ & & & \\
\hline Mergus merganser & $\mathrm{LC}$ & $\mathrm{U}$ & 0.92 & & & & & & & & & & & & & & & $\times$ & & & $\times$ \\
\hline M. serrator & LC & $\mathrm{U}$ & 0.92 & & & & & & & & & & & & & & & $\times$ & & & \\
\hline Mergellus albellus & LC & MI & 0.89 & & & & & & & & & & & & & & & & & & \\
\hline Oxyura leucocephala & EN & $\mathrm{U}$ & 0.93 & & & & & & $x$ & & & & & & $x$ & & & $x$ & & & $x$ \\
\hline
\end{tabular}


Table 1. Continued.

\begin{tabular}{|c|c|c|c|c|c|c|c|c|c|c|c|c|c|c|c|c|c|c|c|}
\hline & \multicolumn{3}{|c|}{$\begin{array}{l}\text { Human intrusion } \\
\text { and disturbance }\end{array}$} & \multicolumn{3}{|c|}{$\begin{array}{l}\text { Natural systems } \\
\text { modifications }\end{array}$} & \multicolumn{6}{|c|}{ Invasive and other problematic species } & \multicolumn{6}{|c|}{ Pollution } & \multirow{2}{*}{$\begin{array}{l}\text { Geological } \\
\text { events } \\
\text { 10 }\end{array}$} \\
\hline & 6.1 & 6.2 & 6.3 & 7.1 & $7 \cdot 2$ & $7 \cdot 3$ & 8.1 & 8.2 & 8.3 & 8.4 & 8.5 & 8.6 & 9.1 & 9.2 & $9 \cdot 3$ & 9.4 & 9.5 & 9.6 & \\
\hline Cygnus olor & & & & & $x$ & $x$ & & $x$ & & & $x$ & & & $\times$ & $\times$ & & & & \\
\hline C. Cygnus & & & & & $x$ & & & $\times$ & & & $x$ & $\times$ & $\times$ & $\times$ & $x$ & & & & \\
\hline C. bewickii & & & & & $x$ & $\times$ & & $x$ & & & $x$ & $\times$ & $\times$ & $\times$ & $\times$ & & & & \\
\hline Anser anser & & & & & $x$ & & & $\times$ & & & & $\times$ & $\times$ & $x$ & & & & & \\
\hline A. albifrons & & & & & $x$ & & & $x$ & & & & $\times$ & & $x$ & & & & & \\
\hline A. erythropus & & & & & $x$ & & & $x$ & & & $x$ & $x$ & & $x$ & & & & & \\
\hline Tadorna tadorna & & & & & $x$ & & & $x$ & & & $x$ & & & $x$ & $\times$ & & & & \\
\hline T. ferruginea & & & & & $x$ & & & $x$ & & & $x$ & & & $x$ & $\times$ & & & & \\
\hline Anas platyrhynchos & & & & & $x$ & & & & & & $x$ & & & & $\times$ & & & & \\
\hline A. strepera & & & & & $x$ & & & & & & $x$ & & $\times$ & & $\times$ & & & & \\
\hline A. acuta & & & & & $x$ & & & & & & & & & & $x$ & & & & \\
\hline A. clypeata & & & & & $x$ & & & & & & & & & $x$ & $x$ & & & & \\
\hline A. crecca & & & & & $x$ & & & & & & $x$ & & & & $\times$ & & & & \\
\hline A. querquedula & & & & & $x$ & & & & & & $x$ & & & & $x$ & & & & \\
\hline A. Penelope & & & & & $x$ & & & & & & $x$ & & & & $\times$ & & & & \\
\hline $\begin{array}{l}\text { Marmaronetta } \\
\text { angustirostris }\end{array}$ & $x$ & & & & $x$ & $\times$ & & & & & $x$ & & & $x$ & $\times$ & & & & \\
\hline A. ferina & & & & & $x$ & & & & & & $x$ & & & & & & & & \\
\hline Netta rufina & & & & & $x$ & & & & & & $x$ & & & & & & & & \\
\hline A. marila & & $x$ & & & $x$ & & & & & & & & & & & & & & \\
\hline Bucephala clangula & & & & & $x$ & & & & & & $x$ & & & & & & & & \\
\hline A. fuligula & & & & & $x$ & & & & & & $x$ & & & & & & & & \\
\hline A. nyroca & & & & & $x$ & & & & & & $x$ & & & & & & & & \\
\hline Mergus merganser & & & & & $x$ & & & & & & & & & $x$ & & & & & \\
\hline M. serrator & & & & & $x$ & & & & & & $x$ & & & $\times$ & & & & & \\
\hline Mergellus albellus & & & & & $x$ & & & & & & $\times$ & & & $\times$ & & & & & \\
\hline Oxyura leucocephala & & & & & $x$ & & & & & & $x$ & & & & & & & & \\
\hline
\end{tabular}

Cygnus olo

A. albifron

A. erythropus

T. ferruginea

Anas platyrhynchos

A. clypeat

A. crecca

Marmaronetta

A. ferina

Netta rufina

A. fuligula

M. serrator

Oxyura leucocephala 


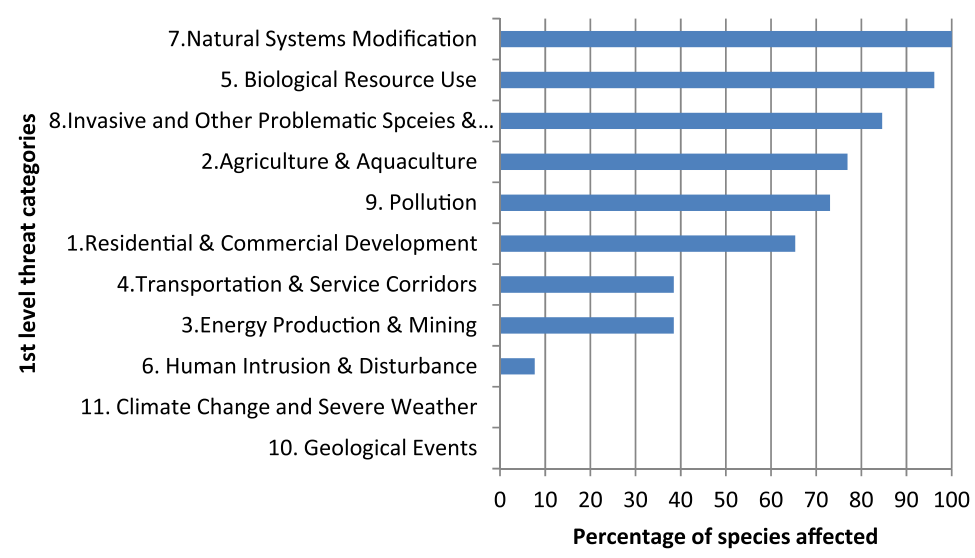

Figure 2. Medium-impact $1^{\text {st }}$ level threats to Anatidae in Iran. Categories of threat follow Salafsky et al. (2008).

these threats. Problematic species and diseases, agricultural activities, pollution, and residential and commercial development were other threats facing these species. Generally, a high number of threats were identified as impacting the 26 species evaluated, even among those considered to be in low risk categories at a global level, adding weight to the assertion that the identification of the precise threat causing a change in population status or risk status, remains problematic and complex (Mace et al. 2008, Di Fonzo et al. 2013). To clarify the mechanism and importance of each of the top five $1^{\text {st }}$ level threat categories identified in this study, they are discussed below and relevant examples, mitigation challenges, and possible solutions are provided.

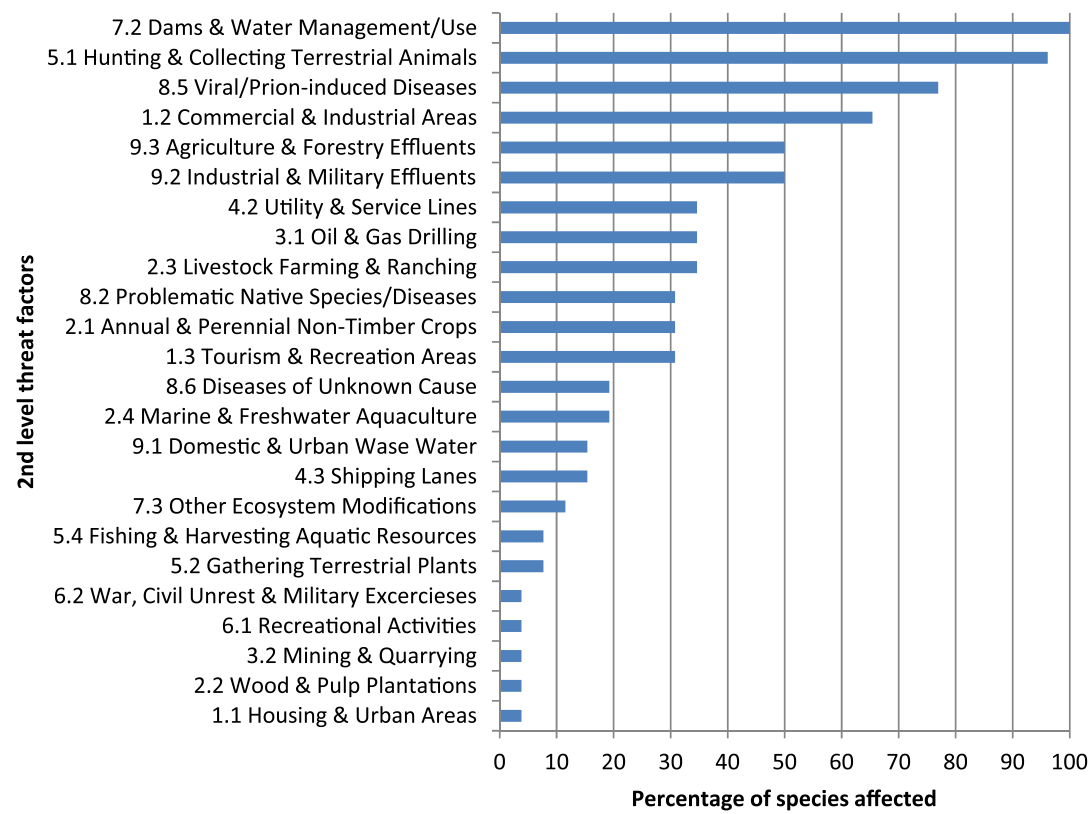

Figure 3. Medium-impact $2^{\text {nd }}$ level threats to Anatidae in Iran. Categories of threat follow Salafsky et al. (2008). 


\section{Natural systems modification}

Habitat loss due to water management and dam construction was identified as the most common threat to Anatidae in Iran. Dam construction without considering the environmental flow of rivers has led to the drying out of numerous wetlands throughout Iran. The high priority that Iran places on development projects has led to inadequate consideration of the environment, conservation, and related issues in decision making (Kaffashi et al. 2011). Natural systems modification, in the form of dams and water management/use, has become a very serious threat affecting Anatidae through habitat loss and degradation. Since Iran is a dry country with an average precipitation of $260 \mathrm{~mm}$ (Modarres 2006), dam construction projects are considered essential to provide water for industrial, agricultural and domestic uses. However, Environmental Impact Assessments for dam construction projects mostly overlook the ecological and environmental outcomes and especially disregard the importance of environmental flow of rivers, and the impact these changes have on biodiversity. Drying out of a number of valuable wetlands in Iran has been attributed to such unreflective decision making, with the most severe case being that of Lake Urumiyeh in the northwest, a very important breeding and wintering ground for waterbirds. A once $5,650 \mathrm{~km}^{2}$ lake in 1998 (Zarghami 2011), Lake Urumiyeh is designated as a National Park, Ramsar site, and UNESCO Biosphere Reserve. Over the last decade, however, $1,500 \mathrm{~km}^{2}$ of the lake has dried out (Zafarnejad 2009) due to intensive water extraction for irrigation (Zarghami 2011) and the construction of 40 dams over major rivers in its watershed (Zafarnejad 2009). Clearly, such reduction in water available to breeding birds can severely limit local waterbird populations, affecting breeding and feeding habitats in quality and extent.

Other examples of lakes drying out due to inadequate water management include Gav Khooni (Isfahan province), Parishan (Fars province), Aji Gol, Ala Gol, Alma Gol (Golestan province), and Ghori Gol (East-Azarbaijan), all considered Important Bird Areas by BirdLife International. Still, restoration projects for wetlands are not a priority in Iran. Even for the case of Lake Urumiyeh, with its national and international importance, various restoration projects such as determining water transfer routes from other basins to the lake (Zarghami 2011) have been proposed but are far from implementation.

\section{Biological resource use}

Commercial and recreational hunting has long been a major threat to Anatidae especially in northern Iran (Popovkina 2006). This activity, which was found to have medium level impact on $96 \%$ of species evaluated in this study, is an important source of income for local people. Overhunting is a major threat affecting waterbirds, especially ducks, geese and Eurasian Coot Fulica atra, in large wetlands in the south Caspian lowlands (Pahlavani 2007, Mansoori 2009). Hunting pressure has increased greatly since the 1970s, especially at important wetlands such as Anzali wetland complex, Gilan Province, south-west of the Caspian Sea (Mansoori 2009). This rise in hunting pressure has been attributed to the increased accessibility of wetlands due to road construction, as well as the increased domestic production and import of hunting firearms that has made shotguns available to the general public through legal and illegal means. The waterfowl harvest in Gilan province indicates that Anatidae are the most abundantly hunted waterbirds (Popovkina 2006). Common Teal Anas crecca and Mallard A. platyrhynchos, along with Eurasian Coot, account for over $80 \%$ of birds identified in a local market in this province (Ashoori 2008).

Illegal and highly destructive hunting methods, implemented throughout Iran, have resulted in rapid declines in Anatidae populations. An example of these methods is carried out in Fereidoon-kenar "damgahs" (Mazandaran province, northern Iran) where traditional, reportedly sustainable, hunting methods are practised followed by recently developed inhumane methods that exterminate waterbirds, especially ducks. Damgahs are rice paddies that are flooded in autumn and winter and walled up by tall hedges or trees to provide a secure food-rich habitat for attracting migrating birds. The traditional method of hunting involves training decoy ducks to attract wild birds into 
traps (Scott 1995). This method, if practised alone, is thought to be a sustainable method of hunting, since not many birds can be caught at once (Alireza Hashemi, Tarlan Birdwatching and Ornithological Group, pers. comm. 2013). In Fereidoon-kenar, however, because of the high concentration of birds, other methods accompany the traditional ones in order to maximise profit. Aerial nets are set up near damgahs at night to trap any flocks of birds flying through the area. These nets, with very small mesh size, catch not only migratory waterbirds, but also many other non-target birds. With a decrease in the abundance of birds in the damgahs, when net trapping is not profitable anymore, large-scale shoots extirpate the remaining birds. Hunted birds are sold in the local market, where globally threatened species such as White-headed Duck, among other non-commercial birds that have been trapped in the aerial nets, such as Barn Owls Tyto alba, Eurasian Bitterns Botaurus stellaris, and egrets Ardeidae are offered for sale.

Hunting regulations during the hunting season in Iran, including the length of hunting season, daily opening and closing times, daily bag limits, and total possession limits (Popovkina 2006), although in place, do not seem to be effective in managing commercial harvest of Anatidae species. Since hunting birds is considered to be a legitimate activity by local people, implementing effective management to reduce this important threat factor is very challenging. 'Near Threatened' species such as Ferruginous Duck Aythya nyroca (Popovkina 2006, Ashoori 2008) and threatened species like Marbled Teal (VU) and White-headed Duck (EN) are also found among the hunted species in Iran, suggesting the incompetence of DOE in controlling hunting activities. In some regions, such as the Fereidoon-kenar damgahs, local actions overrule national DOE regulations and therefore any attempts to imposing control on hunting activities are unsuccessful (Mansoori 2009).

Stricter implementation of hunting regulations, increasing awareness among local people and hunters about threatened species, encouragement of traditional duck hunting methods instead of modern destructive ones, forming hunting clubs for sport hunters to allow their activities to be managed, improving protection of important wetlands under the national law (national protected areas and Ramsar sites), and the establishment of additional hunting-restricted areas at other wetlands are possible mitigation methods for this threat factor while providing legal hunting opportunities at the same time.

\section{Invasive and other problematic species and diseases}

In 2005, outbreaks of highly pathogenic avian influenza were reported in Central Asia and Eastern Europe (Defra 2005). Waterbirds, especially the order Anseriformes, are known to be the natural reservoir for Avian Influenza Viruses (AIV) (Stallknecht 2003), with the viruses being most prevalent in dabbling ducks, especially Mallard (Olsen et al. 2006, Vandegrift et al. 2010). In a study on AIV in waterbirds wintering in Iran, Fereidouni et al. (2010) confirmed this was true in Iran as well.

Amini and Sehhatisabet (2007) reported an outbreak of the highly pathogenic avian influenza virus in the winter of 2005/2006 which, among other species, led to the death of 334 swans in Gilan province. The outbreak of the virus in 2006/2007 made it impossible for local people in northern Iran to harvest or sell any ducks (Mansoori 2009). Loss of wetland habitats due to unsustainable water management and droughts leads to concentration of higher waterfowl densities in alternative wetlands which can in turn increase influenza transmission within flocks of the same species as well as cross-species transmissions (Vandegrift et al. 2010). Waterbird losses from various types of diseases are much greater now than they have been for nearly a century because habitat loss has reduced the resilience of wildlife populations to the impacts of disease (Friend 2006). Monitoring the quantity of suitable habitat for Anatidae and disease surveillance programmes are necessary to mitigate the problems caused by this serious threat factor in Iran.

Another second level threat category that has recently imposed negative effects on swans, geese, Common Shelducks Tadorna tadorna, and Ruddy Shelducks T. ferruninea is problematic native species/diseases. These waterfowl species depend on grasslands to feed. Such grassland in 
Bujagh National Park in northern Iran, a major wintering and stop over site for waterbirds, is gradually moving through successional stages, with an overgrowth of sedges Carex spp. that facilitates the establishment of bramble Rubus fruticosus scrub. If these plants are not cleared out, Alnus spp. will replace the scrub, and the grassland habitat will eventually reach its climax as Hyrcanian forest. Although this is a natural process, this gradual loss of wintering grounds is a growing concern especially for the species mentioned and has been reported to be a threat in Russia as well (Grishanov 2006). Management for such grasslands focuses on prevention of colonisation by scrub and trees (Ausden 2004). To conserve these valuable grassland habitats, actions are needed to set back succession by livestock grazing or mechanical removal of problematic plants.

\section{Agriculture and aquaculture}

Habitat loss due to agriculture is the most severe threat to birds worldwide (BirdLife International 2008, Vié et al. 2009). The major drivers of population declines in Palearctic-Afrotropical migratory birds are agriculture and deterioration of habitat quantity and quality in non-breeding areas (Kirby et al. 2008). These were not identified as the most important threats affecting Anatidae in Iran. However, the low relative ranking is likely to be because wetlands in Iran are mostly protected by law, either as national protected areas or Ramsar sites, so loss of land to agriculture is limited. National regulations prohibit changes in land use in these areas, therefore, although wetland drainage for agricultural activities affect many wetlands to various extents (Ashoori et al. 2007, Ra'naghad and Ebrahimi 2007, Scott 2007, Behrouzi-Rad 2008, Mansoori 2009, Faramarzi 2012), converting wetlands to agriculture is no longer commonly practiced in Iran. The problem of intensive agriculture in wetland margins remains severe, however, and other threats which result in degradation of habitat quality are present. Agricultural activities adjacent to wetlands not only cause disturbance and pollute the wetlands, but also result in the loss of marginal habitats such as grasslands and pasturelands.

Livestock ranching is a contradictory issue, affecting some species positively and some negatively. Species that depend on grasslands to feed (swans, geese, Common Shelduck, Ruddy Shelduck) benefit from livestock grazing as it sets back succession and maintains the area of grassland habitats (Sutherland and Hill 1995). Nevertheless, livestock ranching is recorded as a threat to species that breed in wetland marginal habitats since it reduces reproductive success by causing damage to nests, eggs, and chicks.

Wetland agriculture is vital for poverty reduction, but requires careful planning. Elimination of agricultural activities in and around wetlands is not socially and economically appropriate unless the wetland in question is protected by national regulations where any form of human development is prohibited. Management plans therefore need to consider both the conservation issues and livelihood requirements of local people (McCartney et al. 2011). The effects of agricultural activities on different species must also be considered since activities such as livestock grazing are essential for the conservation of some species but detrimental for others.

\section{Pollution}

Pollution entering wetlands from various sources affects waterbirds mostly through habitat degradation. Many important wetlands in Iran are fed by rivers that pass through residential and agricultural land. Untreated sewage from urban areas as well as effluents from agricultural and industrial units are discharged into wetlands either directly or through polluted rivers (Behrouzi-Rad 2008, Jafari 2009). Also, effluents from industrial units such as oil refineries in the south (e.g. affecting Shadegan wetland, Khuzestan province) (Zamani-Ahmadmahmoodi et al. 2009, Kaffashi et al. 2011) and pollution from oil extraction activities in the Caspian sea in the north (e.g. Gomishan wetland, Golestan province and Anzali wetland complex) (Behrouzi-Rad 2008) are causes of degradation of some major wetland systems in Iran. 
Pesticide and fertiliser run-off from intensive agriculture that is practised at the boundaries of many of the important wetlands (Mansoori 2009, Zamani-Ahmadmahmoodi et al. 2009, Ghafouri et al. 2010, Karimi et al. 2012) seriously affects the ecology of wetlands and impacts waterbird communities. Livestock manure is also a source of wetland pollution (Mansoori 2009).

The first step in tackling the problem of pollution in wetlands is to identify point and non-point sources of pollution and to determine the contribution of each source to the pollution of important wetland habitats and consequently to the waterbirds depending on them. Industrial units and human habitation in northern Iran, where the most important wintering sites for Anatidae are located, lack appropriate wastewater treatment plants (Jafari 2009). The establishment of urban and domestic wastewater treatment plants as well as the use of environmental management strategies for pollution prevention and waste minimisation in industrial units can be helpful for reducing the pollution load of wetlands.

\section{Residential and commercial development}

Illegal construction around wetlands, including human habitation (e.g. in Anzali wetland complex), recreation and tourism developments (e.g. in Lake Urumiyeh), and industrial and military areas (e.g. in Hoor-al-Azim and Shadegan wetlands, Khouzestan province) are major threats to many wetlands in Iran (Behrouzi-Rad 2008), reducing the area of suitable habitat for Anatidae.

Although residential and commercial development around and within many wetlands (those designated as protected areas or considered internationally important) is prohibited by national laws and regulations, halting such projects is almost impossible, considering the high priority that the government places on development strategies. In order to mitigate this threat factor, there is a need for more effective law enforcement and monitoring as well as implementation of Environmental Impact Assessment (EIA) for projects that affect wetlands.

\section{Conclusion}

Although our results indicate that taken as a whole, the threat factors driving change in status of Anatidae in Iran are likely to be of medium rather than high impact, the diversity of threats identified, affecting both globally threatened and non-threatened birds, shows the vulnerability of this group of waterbirds. Human-induced climate change is known as the most important threat affecting birds in the long-term (Vié et al. 2009). It is also known to be one of the most serious threats to migratory birds worldwide (Kirby et al. 2008). Due to insufficient background knowledge on the effects of climate change in Iran, it was not possible to accurately identify and score this threat factor for Anatidae. It is worth noting however, that climate change may influence and exacerbate some of the other threat factors that we have listed.

Although habitat loss is considered an important threat to birds worldwide (Vié et al. 2009) and was found to be the most important threat to Anatidae in Iran, since the species under review are economically valuable, hunting also appears to be a very serious problem. It is arguable that hunting might be a more important threat than dam construction and water management, due to its targeted impact and resultant rapid reduction in population size of a given target species. The magnitude of exploitation is so high in some areas that the effects of habitat degradation in suitable habitats used by waterbirds as a stop-over or wintering area are likely to remain insignificant in comparison to the primary threat.

The published method we used for identifying and scoring threat factors was necessarily subjective but consistent, providing a broad picture of conservation threats to Anatidae in the country, but lacking detailed and quantitative data. A more quantitative understanding of the impact of threats of different magnitude, scope and severity remains problematic (Di Fonzo et al. 2013). Although we tried to ensure that respondents identified threats in a unified context (integrating scope and severity) and we achieved high level of consistency of answers to our questionnaire, the significance of different threats was inevitably assessed differently by riskaverse respondents and those who were more evidentiary in their approach. We believe however, 
given the scarcity of documented data on threats to Anatidae in Iran, the threat factors identified in this study provide the necessary grounds for national Red List assessment of this important group of birds. Identification of the most important threat factors is imperative for various stages of Red List assessment, including calculating the number of "locations", choosing the best scale for calculating geographic range metrics, and inference or projection of changes in populations (IUCN 2001). Also, since the best criteria for assessing each species are based on the major threat factors (Milner-Gulland et al. 2006), the results of this study are of paramount importance to the process of national Red List assessment as well as threat assessment at the flyway scale.

\section{Supplementary material}

The supplementary materials for the article can be found at journals.cambridge.org/bci

\section{Acknowledgements}

We thank Alireza Hashemi, Mohammad Tohidifar, Hamid Amini, Zahra Elahi Rad, Maryam Omidi, Ramezan Ali Ghaemi, Mojtaba Hosseini, Mohammad Reza Bathaei, Daryoush Moghadas, Ali Khani, Mahmoud Shakiba, and Meysam Ghasemi for their responses to the threats identification questionnaires. We are also grateful to Dr. Afshin Danehkar for his suggestions for improving the format of the questionnaire, Mina Farhoodinia for her assistance in population data collection and compilation, and Dr. Arco Van Strien for his help with implementing and interpreting TRIM analysis.

\section{References}

Amini, H. and Sehhatisabet, M. E. (2007) Wintering populations of swans in Iran. Podoces 2: 113-121.

Ashoori, A. (2008) Birds offered for sale in the Langarud market, southwestern Caspian Sea. Podoces 3: 97-131.

Ashoori, A., Barati, A. and Reihanian, H-R. (2007) Recent observations of the Red Phalarope Phalaropus fulicarius at Boujagh National Park, Gilan Province, and Agh Gol Wetland, Hamedan Province and its status in Iran. Podoces 2: 148-150.

Ausden, M. (2004) Habitat management. In W. J. Sutherland, I. Newton and R. Green, eds. Bird ecology and conservation: A handbook of techniques. New York, USA: Oxford University Press.

Behrouzi-Rad, B. (2008) Wetlands of Iran. Tehran: National Geographical Organization Publication. [In Persian].

BirdLife International (2008) State of the world's birds: indicators for our changing world. Cambridge, UK: Birdlife International.

BirdLife International (2010) Threats, stresses and impacts. Birdlife International. http:// www.birdlife.org/datazone/info/spcthreat [Accessed September 2012].
BirdLife International (2013) Country profile: Iran, Islamic Republic of. http://www. birdlife.org/datazone/country/iran [Accessed December 2012].

Boere, G. C. and Stroud, D. A. (2006) The flyway concept: what it is and what it isn't Pp. 40-47 in G. C. Boere, C. A. Galbraith and D. A. Stroud, eds. Waterbirds around the world. Edinburgh, UK: The Stationery Office.

Cronbach, L. J. (1951) Coefficient alpha and the internal structure of tests. Psychometrika 16: $297-334$.

Croxall, J. P., Butchart, S. H., Lascelles, B., Stattersfield, A. J., Sullivan, B., Symes, A. and Taylor, P. (2012) Seabird conservation status, threats and priority actions: a global assessment. Bird Conserv. Internatn. 22: 1-34.

Davidson, N. C. and Stroud, D. A. (2006) African-Western Eurasian flyways: current knowledge, population status and future challenges. Pp. $63-73$ in G. C. Boere, C. A. Galbraith and D. A. Stroud, eds. Waterbirds around the world. Edinburgh, UK: The Stationery Office.

Defra (2005) Highly pathogenic avian influenza (H5N1) in Eastern Europe. London, UK: Department for Environment, Food and 
Rural Affairs, International Animal Health Division.

Di Fonzo, M., Collen, B. and Mace, G. M. (2013) A new method for identifying rapid decline dynamics in wild vertebrate populations. Ecol. Evol. 3: 2378-2391.

DOE (2004) Environmental rules and regulations. Tehran, Iran: Iran Department of Environment Publication.

Evans, M. I. (1994) Important bird areas in the Middle East. Cambridge, UK: BirdLife International.

Faramarzi, N. (2012) Agricultural water use in Lake Urmia basin, Iran: An approach to adaptive policies and transition to sustainable irrigation water use. Uppsala, Sweden: Uppsala University.

Fereidouni, S. R., Werner, O., Starick, E., Beer, M., Harder, T. C., et al. (2010) Avian influenza virus monitoring in wintering waterbirds in Iran, 2003-2007. Virol J. 7: 1754-1757.

Friend, M. (2006) Evolving changes in diseases of waterbirds. Pp. 412-417 in G. C. Boere, C. A. Galbraith and D. A. Stroud, eds. Waterbirds around the world. Edinburgh, UK: The Stationery Office.

Ghafouri, M., Ghaderi, N., Tabatabaei, M., Versace, V., Ierodiaconou, D., Barry, D. and Stagnitti, F. (2010) Land use change and nutrients simulation for the Siah Darvishan basin of the Anzali wetland region, Iran. Bull. Environ. Contam. Toxicol. 84: 240-244.

Goriup, P. and Tucker, G. (2007) Assessment of the merits of a CMS instrument covering migratory raptors in Africa and Eurasia. London, UK: Department for Environment, Food and Rural Affairs, Wildlife Species Conservation Division.

Grishanov, D. (2006) Conservation problems of migratory waterfowl and shorebirds and their habitats in the Kaliningrad region of Russia. P. 354 in G. C. Boere, C. A. Galbraith and D. A. Stroud, eds. Waterbirds around the world. Edinburgh, UK: The Stationery Office.

Isakov, Y. (1967) MAR project and conservation of waterfowl breeding in the USSR. Pp. $125-138$ in Z. Salverda, ed. Proceedings of the Second European Meeting on Wildfowl Conservation, Noordwijk aan Zee, the Netherlands. The Netherlands: Ministry of Cultural Affairs, Recreation and Social Welfare.
IUCN (2001) IUCN Red List categories and criteria: Version 3.1. Gland, Switzerland and Cambridge, UK: IUCN Species Survival Commission. IUCN.

IUCN and CMP (2006) IUCN - CMP unified classification of direct threats, ver. 1.0. Gland, Switzerland: IUCN and CMP.

Jafari, N. (2009) Ecological integrity of wetlands, their functions and sustainable use. J. Ecol. Nat. Env. 1: 45-54.

Jennings, D. E. and Rohr, J. R. (2011) A review of the conservation threats to carnivorous plants. Biol. Conserv. 144: 1356-1363.

Kaboli, M., Aliabadian, M., Tohidifar, M., Hashemi, A. and Roselaar, C. S. (2012) Atlas of birds of Iran. Tehran, Iran: Iran Department of Environment.

Kaffashi, S., Shamsudin, M. N., Radam, A., Rahim, K. A., Yacob, M. R., Muda, A. and Yazid, M. (2011) Economic valuation of Shadegan International Wetland, Iran: notes for conservation. Regional Env. Change. 11: 925-934.

Karimi, F., Moattar, F., Farshchi, P., Savari, A. and Parham, H. (2012) Ecological risk assessment of agricultural pesticides throughout the Shadegan wetland, Iran. J. Agric. Sci. 4: 109-116.

Khaleghizadeh, A., Scott, D. A., Tohidifar, M., Musavi, S. B., Ghasemi, M., et al. (2011) Rare birds in Iran in 1980-2010. Podoces. 6: 1-48.

Kirby, J. S., Stattersfield, A. J., Butchart, S. H. M., Evans, M. I., Grimmett, R. F. A., Jones, V. R., O'Sullivan, J., Tucker, G. M. and Newton, I. (2008) Key conservation issues for migratory land- and waterbird species on the world's major flyways. Bird Conserv. Internatn.

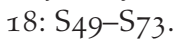

Mace, G. M., Collar, N. J., Gaston, K. J., Hilton-Taylor, C., Akçakaya, H. R., LeaderWilliams, N., Milner-Gulland, E. and Stuart, S. N. (2008) Quantification of extinction risk: IUCN's system for classifying threatened species. Conserv. Biol. 22: 1424-1442.

Mansoori, J. (2009) The avian community of five Iranian wetlands, Miankaleh, FereidoonKenar, Bujagh, Anzali and Lavandevil, in the South Caspian lowlands. Podoces. 4 : 44-59.

Mansoori, J. and Amini, H. (2011) Current status of the Lesser White-fronted Goose Anser erythropus in Iran. Podoces. 6: 123-125. 
McCartney, M., Rebelo, L. M., Senaratna Sellamuttu, S. and de Silva, S. (2011) Wetlands, agriculture and poverty reduction. Colombo, Sri Lanka: International Water Management Institute.

Milner-Gulland, E. J., Kreuzberg-Mukhina, E., Grebot, B., Ling, S., Bykova, E., et al. (2006) Application of IUCN red listing criteria at the regional and national levels: A case study from Central Asia. Biodivers. Conserv. 15: $1873-1886$.

Modarres, R. (2006) Regional precipitation climates of Iran. J. Hydrol. 45: 13-27.

Nunnally, J. C. (1978) Psychometric theory. New York: McGraw-Hill.

Ocock, J., Baasanjav, G., Baillie, J. E. M., Erbenebat, M., Kottelat, M., Mendsaikhan, B. and Smith, K. (2006) Mongolian Red List of fishes. London: Zoological Society of London. (Regional Red List Series Vol. 3).

Olsen, B., Munster, V. J., Wallensten, A., Waldenström, J., Osterhaus, A. D. and Fouchier, R. A. (2006) Global patterns of influenza A virus in wild birds. Science. 312: $384-388$.

Pahlavani, A. (2007) A survey of waterbird hunters in Gomishan wetland, southeast Caspian Sea. Podoces. 2: 160-162.

Pannkoek, J. and van Strien, A. (2005) TRIM 3 manual (trends and indices for monitoring data). Voorburg, The Netherlands: Statistics Netherland.

Popovkina, A. (2006) Conflicting trends in Ruddy Shelduck Tadorna ferruginea populations: a myth or reality? Pp. 480-48I in G. C. Boere, C. A. Galbraith and D. A. Stroud, eds. Waterbirds around the world. Edinburgh, UK: The Stationery Office.

Ra'naghad, H. and Ebrahimi, A. (2007) The status of Common Crane Grus grus and Demoiselle Crane Anthropides virgo in West Azarbaijan, Northwest Iran. Podoces. 2: 154-155.

Roselaar, C. S. and Aliabadian, M. (2009) Review of rare birds in Iran, 1860s-1960s. Podoces. 4: 1-27.

Salafsky, N., Salzer, D., Stattersfield, A. J., Hilton-Taylor, C., Neugarten, R., et al. (2008) A standard lexicon for biodiversity conservation: Unified classifications of threats and actions. Conserv. Biol. 22: 897-911.
Scott, D. A. (1995) A directory of wetlands in the Middle East. Gland, Switzerland: IUCN.

Scott, D. A. (2007) A review of the status of the breeding waterbirds in Iran in the 1970s. Podoces. 2: 1-21.

Scott, D. A. (2010) Results of mid-winter waterbird counts in Iran in the early 1970s. Podoces. 5: 11-28.

Scott, D. A. and Rose, P. M. (1996) Atlas of Anatidae populations in Africa and western Eurasia. Wageningen, The Netherlands: Wetlands International.

Stallknecht, D. E. (2003) Ecology and epidemiology of avian influenza viruses in wild bird populations: waterfowl, shorebirds, pelicans, cormorants, etc. Avian Dis. 47: 61-69.

Stroud, D. A., Boere, G. C., Galbraith, C. A. and Thompson, D. B. A. (2006) Waterbird conservation in a new millennium - where from and where to? Pp. 29-39 in G. C. Boere, C. A. Galbraith and D. A. Stroud, eds. Waterbirds around the world. Edinburgh, UK: The Stationery Office.

Sutherland, W. J. and Hill, D. A. (1995) Managing habitats for conservation. Cambridge, UK: Cambridge University Press.

Vandegrift, K. J., Sokolow, S. H., Daszak, P. and Kilpatrick, A. M. (2010) Ecology of avian influenza viruses in a changing world. Ann. N. Y. Acad. Sci. 1195: 113-128.

Vié, J.-C., Hilton-Taylor, C. and Stuart, S. N., eds. (2009) Wildlife in a changing worldAn analysis of the 2008 IUCN Red List of threatened Species, Gland, Switzerland: IUCN.

Zafarnejad, F. (2009) The contribution of dams to Iran's desertification. Int. J. Environ. Stud. 66: 327-341.

Zamani-Ahmadmahmoodi, R., Esmaili-Sari, A., Ghasempouri, S. M. and Savabieasfahani, M. (2009) Mercury in wetland birds of Iran and Iraq: contrasting resident Moorhen, Gallinula chloropus, and migratory common teal, Anas crecca, life strategies. Bull. Environ. Contam. Toxicol. 82: 450-453.

Zamin, T. J., Baillie, J. E., Miller, R. M., Rodríguez, J. P., Ardid, A. and Collen, B. (2010) National red listing beyond the 2010 target. Conserv. Biol. 24: 1012-1020.

Zarghami, M. (2011) Effective watershed management; case study of Urmia Lake, Iran. Lake Reserv. Manage. 27: 87-94. 


\section{ELHAM NOURANI, MOHAMMAD KABOLI ${ }^{*}$}

Department of Environmental Sciences, Faculty of Natural Resources, University of Tehran, Tehran, Iran.

\section{BEN COLLEN}

Centre for Biodiversity \& Environment Research, Department of Genetics, Evolution E Environment, University College London, London, United Kingdom.

*Author for correspondence,email:mkaboli@ut.ac.ir

Received 6 June 2013; revision accepted 17 July 2014; Published online 26 August 2014 